\title{
DA SALA À TELA: PARA O AFASTAMENTO SOCIAL, VIRTUALIZAÇÃO DO “CURSO DE INCLUSÃO DIGITAL”
}

Jussara Gomes Machado-jussarauefs@gmail.com

Diego do Carmo Silva-diegosilva@ecomp.uefs.br

Natália Silva Rosa - srosanatalia@gmail.com

Rodrigo Damasceno Sampaio - damasceno.s.rodrigo@gmail.com

Grupo PET Engenharias - MEC

Universidade Estadual de Feira de Santana, Colegiado de Engenharia de Computação

Av. Transnordestina, s/n, LABOTEC 3 - Novo Horizonte

44036-900 - Feira de Santana - BA

Pablo Rodrigo Fica Piras - pafipi@uefs.br

PET/MEC Engenharias

Universidade Estadual de Feira de Santana, Departamento de Tecnologia

Av. Transnordestina, $s / n$, Módulo 3 - Novo Horizonte

44036-900 - Feira de Santana - BA

Resumo: Este documento descreve como uma atividade extensionista presencial foi convertida em uma atividade virtual para se manter operacional durante o período de distanciamento social adotado para frear os contágios pelo novo coronavírus. A aproximação do grupo PET Engenharias com a prefeitura de Santa Bárbara originou onze ações que levam o município ao cumprimento dos dezessete Objetivos do Desenvolvimento Sustentável - ODSs - da Plataforma Agenda 2030 da ONU. Das onze ações propostas algumas já foram finalizadas, tendo seus objetivos alcançados, outras estão em desenvolvimento e uma em específico foi suspensa para evitar aglomerações. Essa ação, intitulada "Cursos de Qualificação em Informática", foi convertida em uma ação virtual sem prejuízo no alcance dos seus objetivos. A efetiva aplicação desta está no aguardo da obtenção dos meios instrumentais necessários concomitantemente.

Palavras-chave: Política pública. Qualificação em informática básica. Distanciamento social. ODSs da Agenda 2030

\section{INTRODUÇÃO}

Na sua publicação do livro Cyberculture em 1997 na França (LÉVY, 1999), o filósofo Pierre Lévy vaticinou o advento de uma nova era, a hiperconectada, na qual as informações mais importantes e decisivas estão na internet e passam a transitar exclusivamente pela rede mundial de computadores. Diante desta situação que veio a se comprovar, a exclusão digital foi se conformando como um grave problema social, que conduz inequivocamente à exclusão da plena cidadania. Por isto, as Nações Unidas reconheceram já na década passada que o acesso à internet é um direito humano do século XXI (ONU, 2015), de forma que na Agenda 2030 para o Desenvolvimento Sustentável, os estados-membros reconheceram a importância de desenvolver as sociedades do conhecimento, com base em uma educação inclusiva, equitativa, não discriminatória, com respeito às diversidades culturais. De fato, textualmente, no seu Objetivo $4 \mathrm{diz}$ "Assegurar a educação inclusiva e equitativa e de qualidade, e 
promover oportunidades de aprendizagem ao longo da vida para todos" e especifica no ponto 15 desse Quarto Objetivo da declaração:

"Este é também, no entanto, um momento de enorme oportunidade ... A disseminação da informação e das tecnologias da comunicação e interconectividade global tem um grande potencial para acelerar $\mathrm{o}$ progresso humano, para eliminar o fosso digital e para o desenvolvimento de sociedades do conhecimento, assim como a inovação científica e tecnológica em áreas tão diversas como medicina e energia" (Objetivos do Desenvolvimento Sustentável, ONU, 2015).

O acesso satisfatório às Tecnologias de Informação e Comunicação - TICs, depende de pelo menos cinco disponibilidades, concomitantemente: 1) Instrumental: acesso aos equipamentos (computadores, telefones, tablets etc.); 2) Infraestrutural: disponibilidade de internet, programa e aplicativos; 3) Financeira: acesso aos serviços vinculados aos aspectos supra, instrumentais e infraestruturais, normalmente taxados; 4) Cognitiva: capacitação do usuário para utilizar as ferramentas, o que se vincula de alguma forma com a escolarização; 5) Linguística: compreensão dos códigos e textos, que comumente estão escritos ou são ditos em outras línguas.

Um paradoxo recente, vinculado com estas disponibilidades, ocorreu a começos do mês de abril de 2020, quando o Governo Federal anunciou o aplicativo Caixa Auxílio Emergencial, nas plataformas Android e iOS, para fazer um cadastro e poder receber o auxílio emergencial de $\mathrm{R} \$ 600$, para que os cidadãos desempregados pudessem ter um recursos para a subsistência (FOLHA DE SÃO PAULO, 2020; O GLOBO, 2020), acentuando-se a evidência da necessidade do acesso às TICs para todos, sobretudo a população vulnerável.

Sendo um fenômeno de solução multifatorial, as abordagens e soluções podem ser propostas desde vários pontos de vista, se possível de forma integrada. Os avanços em cobertura tem ido, também paradoxalmente, aumentando nestes tempos de pandemia, com aumento de oferta de redes gratuitas wifi em locais públicos (MELHORES DESTINOS, 1999) e planos de subsídios governamentais e institucionais para pacotes de dados (UEFS, 2020). São tímidos avanços que convergem aos princípios, garantias, direitos e deveres para o uso da rede no Brasil:

"Art. 2 $2^{\circ}$ A disciplina do uso da internet no Brasil tem como fundamento o respeito à liberdade de expressão, bem como: (...) II os direitos humanos, o desenvolvimento da personalidade e o exercício da cidadania em meios digitais; (...) VI - a finalidade social da rede". (Marco Civil da Internet, aprovado por meio da Lei $n^{\circ}$ 12.965 , de 23 de abril de 2014)

Mas, como anotado acima, o letramento digital também é fundamental.

O município de Santa Bárbara tem pouco mais de $347 \mathrm{~km} 2$ e nele residem aproximadamente 21 mil habitantes, metade deles na zona rural. O PIB é de R \$7.770/ano e o IDHM de 0,583 (baixo). As principais fontes de renda do município são a agricultura e a pecuária, com destaque para a produção do milho, feijão e a criação de bovinos e caprinos (IBGE, s.d.). Composto por discentes e egressos dos quatro cursos de engenharia da UEFS 
(Engenharia Agronômica, Engenharia Civil, Engenharia de Alimentos e Engenharia de Computação) e um professor tutor, o grupo PET/MEC Engenharias desenvolve atividades extensionistas em comunidades do interior baiano, contemplando aldeias, quilombos, fundosde-pasto, agrupados ou não em associações e cooperativas, em mais de vinte municípios bahianos (Âgua Fria, Banzaê, Caém, Euclides da Cunha, Licínio de Almeida, Monte Santo, Quixabeira, Santa Bárbara, Uauá, Umburanas, Utinga e Wagner). Em uma combinação harmoniosa de conhecimentos, suas ações coletivas convergem a indissociabilidade do ensino, pesquisa e extensão, ações estas distribuídas entre as vinte e duas atividades presentes no planejamento anual do grupo.

No início do ano de 2018, o PET Engenharias estabeleceu um diálogo com a prefeitura de Santa Bárbara, quando foi convidado a palestrar na inauguração de dois cursos Técnicos de Educação Profissional, a conhecer, os cursos: Técnico em Agroindústria e Técnico em Alimentos e Produção Alimentícia. Desse evento, se originou uma parceria mutualmente benéfica entre o grupo, a Assessoria de Comunicação e as Secretarias: 1. de Educação, 2. de Agricultura e Meio Ambiente e 3. de Desenvolvimento Social do município. Das reuniões subsequentes, foram definidas onze ações que abrangem os campos das quatro engenharias que compõe o grupo, ações essas que convergem ao cumprimento dos dezessete Objetivos do Desenvolvimento Sustentável (ODSs) da Plataforma Agenda 2030, de total interesse do município. Das onze ações propostas, quatro já foram finalizadas, tendo como resultado relatórios e trabalhos publicados (SENA et alii, 2018; OLIVEIRA et alii, 2018; MOTA et alii, 2019).

A ação de número dez (Cursos de Qualificação em Informática) resultou no desenvolvimento do curso "Inclusão Digital", que estava prevista para ser iniciada no primeiro semestre deste ano, no recém-inaugurado espaço "Serviço de Convivência e Fortalecimento de Vínculos" da cidade de Santa Bárbara. No entanto, essa ação foi suspensa para cumprir a recomendação de isolamento social, proposta pela OMS como medida de contenção do novo coronavírus, de modo que o PET Engenharias precisou reinventar sua metodologia para mantê-la operacional.

A virtualização do curso de qualificação "Inclusão Digital", estruturado em três módulos: Informática Básica, Marketing Digital e Oficina de Scratch, conta com vídeo-aulas e apostilas digitais para cada conteúdo abordado. A justificativa para sua execução envolve, além do cumprimento da ODS de número 4 (Educação de Qualidade) no município de Santa Bárbara, o enfrentamento da exclusão digital, que cada vez mais colabora com a exclusão social.

\section{METODOLOGIA ADOTADA}

O curso, inicialmente pensado para a população barbarense, tinha por objetivo iniciar-se no mês de abril no espaço "Serviço de Convivência e Fortalecimento de Vínculos" da cidade de Santa Barbara. A proposta inicial era utilizar o espaço para a aplicação de aulas práticas presenciais, com um orador expondo o conteúdo e monitores atendendo aos alunos. No entanto, o avanço da contaminação por coronavírus levou a universidade a suspender suas atividades presenciais, incluindo as atividades extensionistas. Dessa forma, o PET Engenharias precisou reinventar a metodologia adotada para a aplicação desta atividade. 
(C) COBENGE

"Os desafios para formar hoje o engenheiro do amanhã"
$\mathrm{O1}$ a $\mathrm{O3}$ de dezembro Evento On-line

A versão digital do curso manteve sua estrutura, a qual conta com três módulos, cada um responsável por desenvolver nos alunos habilidades específicas. O primeiro módulo, intitulado "Informática Básica", é focado na aprendizagem do manuseio de um computador, o segundo módulo, intitulado "Marketing Digital" é focado em como os meios digitais podem ser utilizados na divulgação de produtos e serviços, por fim, o terceiro módulo, intitulado "Oficina de Scratch", é focado na aprendizagem lúdica de programação.

A versão digital do curso conta com apostilas e vídeo aulas para cada um dos conteúdos abordados. Estes materiais estarão disponíveis na página do grupo PET Engenharias, bem como em suas redes sociais e no Youtube. Durante um período, o curso estará também disponível através da plataforma Google Classroom, onde os concluintes terão direito a um certificado referente aos módulos cursados. A figura 1 apresenta uma das apostilas desenvolvidas para o curso.

Figura 1 - Apostila "Utilização do Microsoft Excel" desenvolvida para a sexta aula do módulo "Informática Básica"

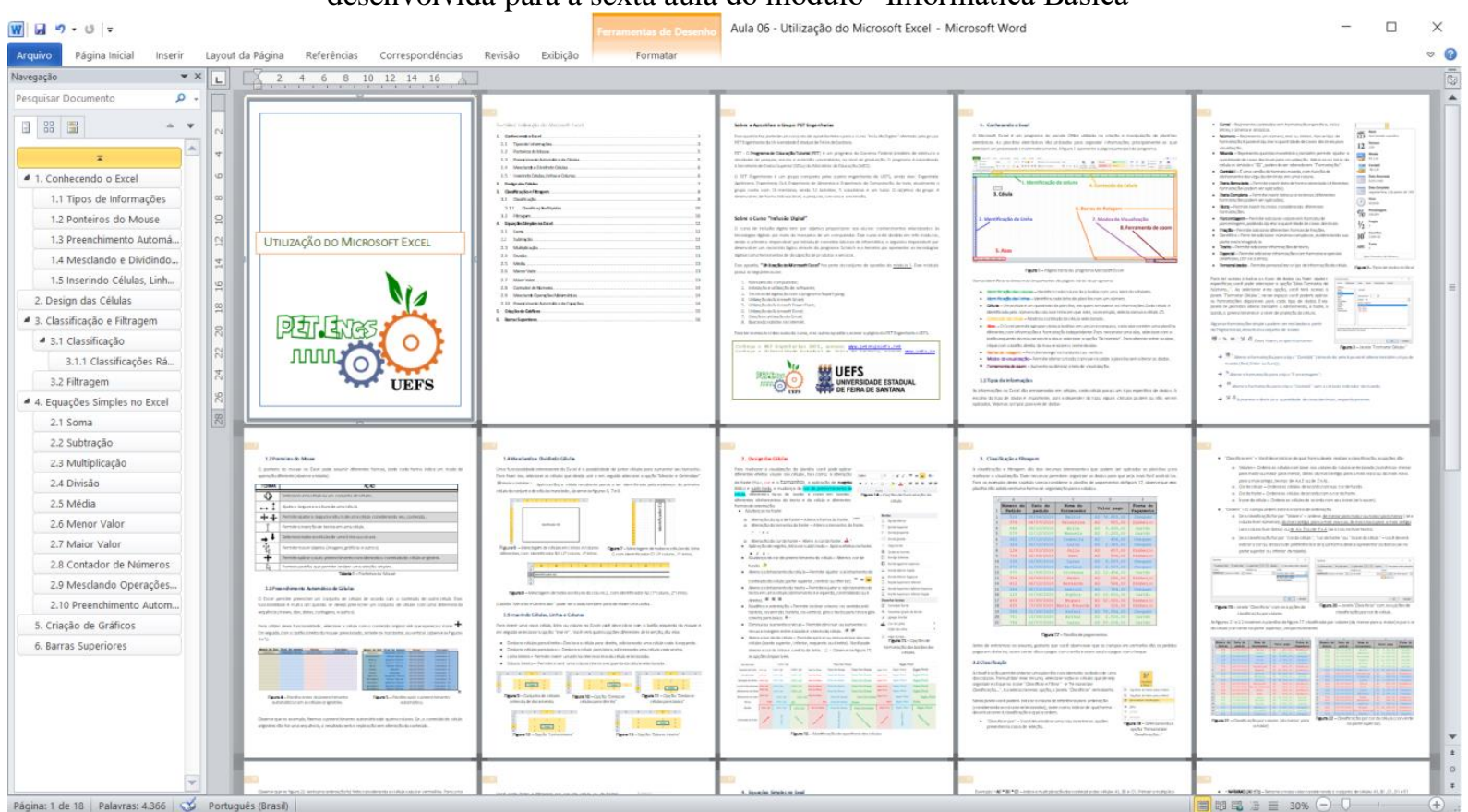

Fonte: Produção do próprio autor.

As subseções seguintes descrevem em detalhes cada módulo do curso.

\subsection{Módulo "Informática Básica"}

O módulo "Informática Básica" tem por objetivo ensinar sobre o manuseio de um computador, a criação e manipulação de arquivos e o acesso à internet. Essa é considerada a etapa mais importante do curso, pois o sucesso na aprendizagem dos conteúdos dos outros módulos depende da familiaridade dos alunos com um computador.

As aulas pensadas para este módulo objetivam: permitir que os alunos desenvolvam conhecimentos sobre o manuseio correto de um computador, bem como permitir que estes diferenciem seus componentes; ensinar sobre o compartilhamento de arquivos, bem como o acesso seguro a internet; ensinar técnicas de digitação, promovendo nos alunos um aumento 
de sua produtividade; desenvolver nos alunos habilidades relacionadas a manipulação de arquivos (documentos, apresentações e planilhas); ensinar sobre a utilização do Gmail, evidenciando seus importantes recursos e; ensinar a fazer buscas na internet, enfatizando a existência de notícias falsas, promovendo nos alunos a capacidade de questionar e averiguar a veracidade das informações. O quadro 1 apresenta o cronograma de aulas do módulo.

Quadro 1 - Cronograma de aulas do módulo "Informática Básica"

\begin{tabular}{|c|c|}
\hline Aula 01 & $\begin{array}{l}\text { Ensinar sobre os equipamentos básicos que compõe o computador } \\
\text { (teclado, mouse, gabinete, entre outros periféricos). Ensinar a ligar e } \\
\text { desligar o computador da forma correta além de gerenciar arquivos e } \\
\text { pastas (criar, mover, excluir, restaurar e outros). }\end{array}$ \\
\hline Aula 02 & $\begin{array}{l}\text { Ensinar a compactar arquivos e instalar programas de forma segura. } \\
\text { Ensinar a baixar arquivos da internet e transferir arquivos entre o } \\
\text { computador e pen-drive. Instalar o software de digitação } \\
\text { "RapidTyping" a ser utilizado na aula sobre digitação. }\end{array}$ \\
\hline Aula 03 & $\begin{array}{c}\text { Ensinar técnicas de digitação utilizando as atividades disponíveis no } \\
\text { software "RapidTyping" instalado na aula anterior. }\end{array}$ \\
\hline Aula 04 & $\begin{array}{l}\text { Ensinar a utilizar o programa Microsoft Word do pacote Office (criar e } \\
\text { editar um documento em branco, editar um modelo pronto de } \\
\text { documento, salvar em diferentes formatos, imprimir). Como atividade, } \\
\text { solicitar a criação de um currículo. }\end{array}$ \\
\hline Aula 05 & $\begin{array}{c}\text { Ensinar a utilizar o programa Microsoft PowerPoint do pacote Office } \\
\text { (criar uma apresentação e utilizar diferentes temas e efeitos de } \\
\text { transição, editar um modelo pronto de apresentação, salvar em } \\
\text { diferentes formatos, imprimir). Como atividade, solicitar a criação de } \\
\text { uma apresentação. }\end{array}$ \\
\hline Aula 06 & $\begin{array}{c}\text { Ensinar a utilizar o programa Microsoft Excel do pacote Office (criar e } \\
\text { editar uma planilha, editar um modelo pronto de planilha, salvar em } \\
\text { diferentes formatos, imprimir). Como atividade, solicitar a criação de } \\
\text { uma tabela que calcula a média de três notas. }\end{array}$ \\
\hline Aula 07 & $\begin{array}{c}\text { Ensinar a criar uma conta do Gmail e a utilizar seus recursos (envio de } \\
\text { e-mail, utilização do Meet, utilização do chat, entre outros). }\end{array}$ \\
\hline Aula 08 & $\begin{array}{l}\text { Ensinar a fazer buscas pela internet. Apresentar sites que } \\
\text { expõem notícias verdadeiras e enfatizar a existência de notícias falsas. }\end{array}$ \\
\hline
\end{tabular}

Fonte: Produção do próprio autor.

\subsection{Módulo "Marketing Digital"}

Nesta etapa do curso os alunos serão capacitados a promover produtos e serviços em meios digitais. Essa etapa é considerada muito importante, pois além de saber manusear um equipamento computadorizado, o aluno será capaz de utilizá-lo a seu favor. No contexto inicial do curso, o módulo de Marketing Digital tinha como principal objetivo oferecer aos barbarenses um meio de promover os produtos e serviços que já comercializam na cidade (em feiras livres e ao entrono da BR116), principalmente os famosos Fabricos de requeijão.

As aulas pensadas para este módulo envolvem a criação de websites, criação de perfil no serviço Google Meu Negócio (com marcação no Google Maps), criação de páginas de divulgação no Facebook e Instagram, criação de conteúdos de divulgação (panfletos, cartazes e cartões de visita) e criação de logomarcas. O quadro 2 apresenta o cronograma de aulas desse módulo. 


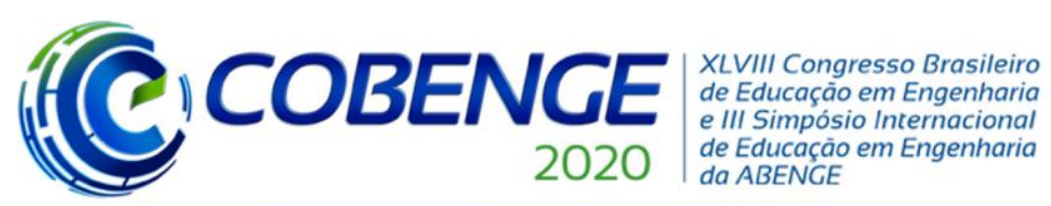

"Os desafios para formar hoje o engenheiro do amanhã"

Quadro 2 - Cronograma de aulas do módulo "Marketing Digital"

\begin{tabular}{|c|c|}
\hline Aula 01 & $\begin{array}{c}\text { Utilização dos recursos gratuitos do Canva - Criação de logomarcas, } \\
\text { cartões, panfletos, cartazes e posts para o Facebook e Instagram. }\end{array}$ \\
\hline Aula 02 & Criação de perfis e páginas de divulgação no Facebook e Instagram. \\
\hline Aula 03 & Criação de sites utilizando o Google Sites. \\
\hline Aula 04 & Criação de Perfil no serviço Google Meu Negócio \\
\hline
\end{tabular}

Fonte: Produção do próprio autor.

Figura 2 - (1) Ambiente de criação de sites do Google Sites; (2) Exemplos de páginas de divulgação no Facebook e Instagram; (3) Ambiente de criação de perfil no Google Meu Negócio e; (4) Exemplos de conteúdos gratuitos criado no Canvas.
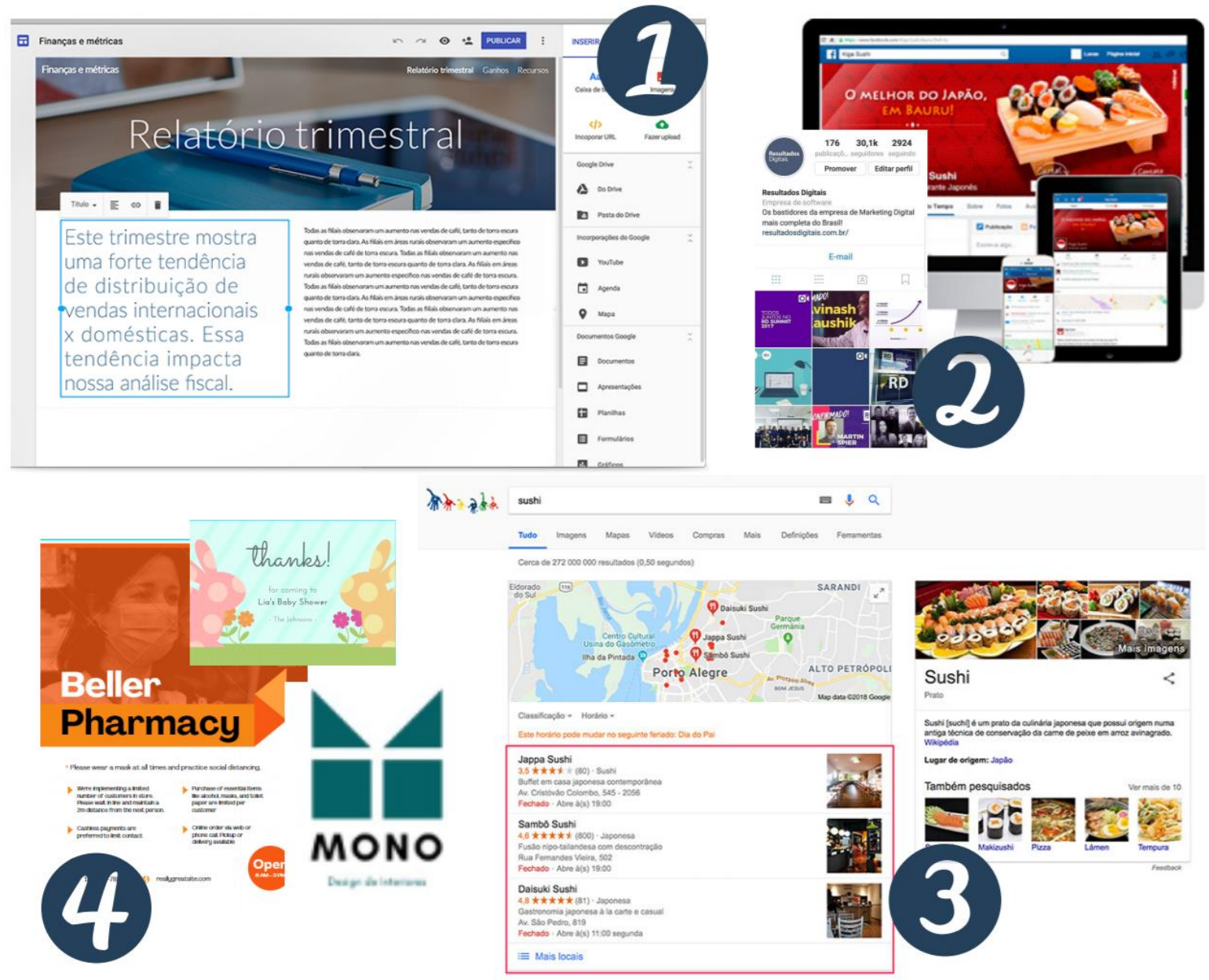

Fonte: Produção do próprio autor.

\subsection{Módulo "Oficina de Scratch"}

O Scratch é uma linguagem de programação, desenvolvida pelo Lifelong Kindergarten Group do MIT Media Lab, que permite a criação de histórias, jogos e animações interativas. Pensado para jovens entre 8 e 16 anos e utilizado entre todos os níveis de ensino (do elementar ao superior) e em múltiplas disciplinas. A proposta do Scratch é desenvolver nos alunos um pensamento critico e sistemático além de promover o trabalho colaborativo (por meio da comunidade Scratch). Seu ambiente de desenvolvimento, compostos por blocos de 
(C) COBENGE

"Os desafios para formar hoje o engenheiro do amanhã"

montagem que simulam comandos de programação, possibilita uma aprendizagem lúdica e convidativa. A figura 3 apresenta o ambiente de desenvolvimento Scratch.

Figura 3 - Ambiente de desenvolvimento Scratch.

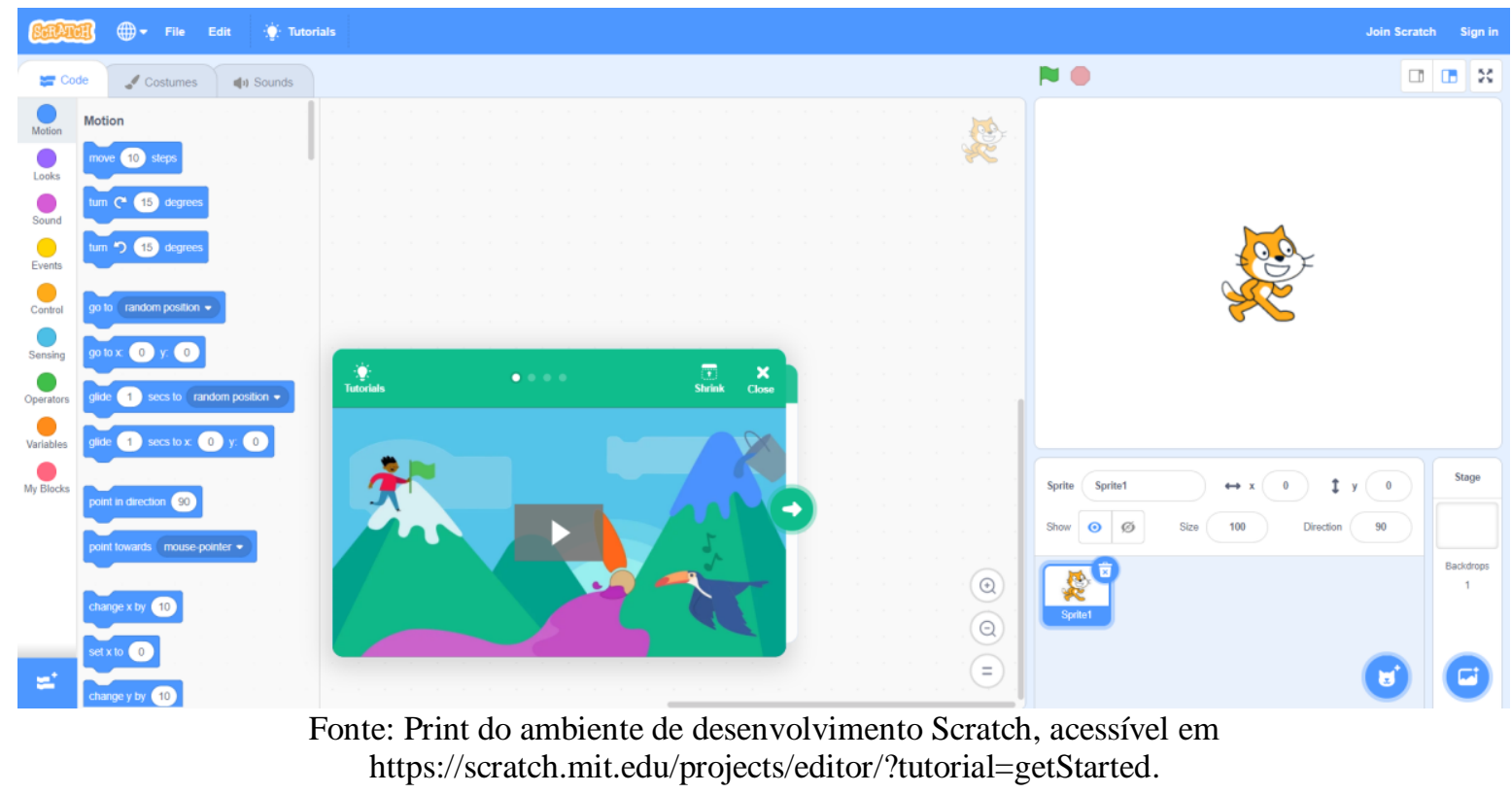

Nesta etapa do curso, o objetivo será o desenvolvimento de habilidades relacionadas à programação, utilizando os jogos como uma metodologia de aprendizagem. Aqui, desenvolveremos, juntamente com os alunos, um jogo digital e por meio deste faremos uma inserção de conceitos importantes, tais como: variáveis, estruturas condicionais, estruturas de repetição, eventos, comando de controle, entre outros.

Os materiais disponíveis para este módulo são focados no desenvolvimento do jogo, de modo que os alunos não se sobrecarreguem com muitas informações. Ao final do curso, espera-se que os interessados em seguir a área de programação (ou seguir como Engenheiros de Computação) tenham adquirido conhecimentos prévios que tornarão sua jornada mais simples.

\section{CONSIDERAÇÕES FINAIS}

O curso de qualificação "Inclusão Digital", em sua versão digital, surgiu como uma estratégia para manutenção das atividades do PET Engenharias durante o período de isolamento social sugerido pela OMS. A criação de conteúdos digitais, e sua publicação em diferentes meios, vêm contribuindo para amenizar os impactos negativos causados pelo distanciamento social além de aumentar a visibilidade do grupo.

Outro aspecto positivo, percebido na adoção dessa nova metodologia, foi que, uma vez desenvolvido um conteúdo digital, sua aplicação em forma de cursos será uma tarefa simples e facilmente replicada. Com isso, o retorno às atividades extensionistas presenciais não excluem a manutenção das atividades virtuais. 
Como comentado, a eficácia no ambiente da cibercultura demanda a realização simultânea de meios instrumentais e infraestruturais que em um município com a metade da população rural e IDMH de 0,583 não permite a aplicação desta sem atingir algumas condições prévias, concomitantemente.

\section{REFERÊNCIAS}

BRASIL. Lei No 12.965, de 23 de abril de 2014, que estabelece princípios, garantias, direitos e deveres para o uso da Internet no Brasil. 2014. Disponível em http://www.planalto.gov.br/ccivil_03/_ato2011-2014/2014/lei/112965.htm. Acesso em 21 de julho de 2020.

FOLHA DE SÃO PAULO. Auxílio emergencial: governo lança aplicativo e site para pedir os R\$600. 2020. Disponível em:

https://economia.uol.com.br/noticias/redacao/2020/04/07/auxilio-emergencialcoronavirus-caixa-aplicativo-app-informal-autonomo-mei.htm?cmpid=copiaecola. Acesso em 21 de julho de 2020.

LÉVY, Pierre. Cibercultura. Editora 34. São Paulo. 231p. 1999.

MELHORES DESTINOS. Wi-Fi grátis do Google: como acessar em São Paulo e outras cidades do mundo. 2019. Disponível em https://www.melhoresdestinos.com.br/wifigratis.html. Acesso em 30 de julho de 2020.

MOTA, Raírio S.; LIMA, Lucas V.R.; QUEIROZ, Manuella V.L.; SANTOS, Rosângela L.; FICA PIRAS, Pablo R.. Atividade extensionista: metodologia de identificação de barragens e aguadas no semiárido baiano, uma aplicação em Santa Bárbara (BA). In: XXIV Encontro Nacional dos Grupos do Programa de Educação Tutorial, 2019, Natal. Anais. UFRN, 2019. pág. 311-22. 2019.

O GLOBO. Ao menos 57 milhões de informais não têm Internet, uma barreira para a distribuição do auxílio emergencial. 2020. Disponível em: https://oglobo.globo.com/economia/ao-menos-57-milhoes-de-informais-nao-teminternet-uma-barreira-para-distribuicao-do-auxilio-emergencial-24400172. Acesso em 21 de julho de 2020.

OLIVEIRA, Poliane K.S.; de SENA, Amanda L; SILVA Juliete S.; MAGALHÃES, Pedro P.G; FICA PIRAS, Pablo R.. Qualificação sanitária como ingrediente do selo de origem no requeijão de Santa Bárbara. In: XIII EBAPET, 2018, Feira de Santana. Apresentação de Pôster. UEFS, 2018.

ONU - Organização das Nações Unidas (2015). Transformando Nosso Mundo: A Agenda 2030 para o Desenvolvimento Sustentável. Disponível em: https://nacoesunidas.org/wp-

SCRATCH. Acerca do Scratch. Disponível em: https://scratch.mit.edu/about. Acesso em: 17 jul. 2020.

SENA, Amanda L.; SILVA, Juliete S.; OLIVEIRA, Poliane K.S.; MAGALHÃES, Pedro P.G.; SILVA, Daniele C.; LIMA, J.R.O; FICA PIRAS, Pablo R.. Associação e qualificação de produtores como ingrediente do selo de origem no requeijão de Santa Bárbara. In: XIII EBAPET, 2018, Feira de Santana. Apresentação de Pôster. UEFS, 2018.

UEFS. UEFS terá edital para auxílio digital. 2020. Disponível em http://www.uefs.br/2020/07/3294/Uefs-tera-edital-para-auxilio-digital.html. Acesso em 30 de julho de 2020. 


\title{
FROM CLASSROOM TO SCREEN: FOR SOCIAL DISTANCING, "DIGITAL INCLUSION COURSE" VIRTUALIZATION
}

\begin{abstract}
This document describes how a face-to-face extension activity was converted into a virtual activity to remain operational during the period of social isolation adopted to new coronavirus curb contagion. The Engineering undergraduates tutorial group is approaching with eleven actions witch with the municipality of Santa Bárbara tend to some aspects for seventeen Sustainable Development Goals - SDGs fulfilment, as part of the UN Agenda 2030 Platform. Some of the proposed actions already been completed, with their objectives achieved, others are under development and one in particular has been suspended to avoid people agglomerations. The action entitled "Qualification Courses in Informatics" was converted into a virtual one, hoping without prejudice to the achievement of its objectives. Its effective application is awaiting the necessary instrumental means concomitantly obtained.
\end{abstract}

Keywords: Public policy. Qualification in basic computer science. Social distancing. Agenda 2030 Sustainable Developments Goals. 